\title{
Urban-Rogers-Meyer syndrome
}

INSERM

\section{Source}

INSERM. (1999). Orphanet: an online rare disease and orphan drug data base. UrbanRogers-Meyer syndrome. ORPHA:3409

This syndrome is characterized by intellectual deficit, short stature, obesity, genital abnormalities, and hand and/or toe contractures. It has been described in two brothers and in one isolated case. The patients also present with generalized osteoporosis and a history of frequent fractures. This syndrome is similar to Prader-Willi syndrome, but the hand contractures and osteoporosis, together with the lack of hypotonia, indicate this is a different entity. 